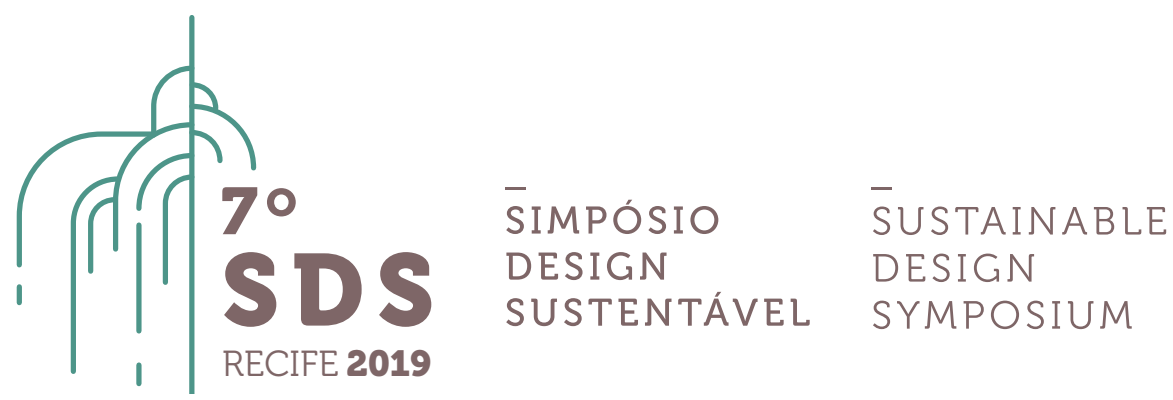

\title{
A importância do envolvimento da comunidade na validação e sustentabilidade de projetos de desenvolvimento de produtos locais
}

\author{
Raquel Canaan ${ }^{1}$, Mara Guerra² \\ ${ }^{1}$ Universidade do Estado de Minas Gerais, Centro de Estudos em Design de Gemas e Joias, raquel.pcanaan@gmail.com \\ ${ }^{2}$ Universidade do Estado de Minas Gerais, Centro de Estudos em Design de Gemas e Joias, maraguerrak@gmail.com
}

\begin{abstract}
A abordagem do design aplicado a projetos em comunidades com o objetivo de oferecer aos atores locais uma nova atividade ou o aprimoramento dos produtos e/ou serviços oferecidos localmente são iniciativas que vêm ocorrendo em todo o país. Porém, nem todas alcançam os resultados almejados quando as ações são finalizadas. Este artigo visa discorrer sobre a importância do envolvimento dos atores locais em todo o processo desenvolvido no território, aumentando as chances de sustentabilidade das propostas, quando o apoio às ações é finalizado e estas ficam nas mãos da comunidade local. Apresenta dois estudos de caso de trabalhos realizados em comunidades de Minas Gerais, buscando demonstrar como a autonomia dada aos atores foi fundamental para que as iniciativas tivessem êxito.
\end{abstract}

Keywords. Design, autonomia, comunidades, desenvolvimento de projetos, atores locais.

\section{Introdução}

De acordo com Dias (2006), “A globalização tem provocado a necessidade de redescobrir e fortalecer sua identidade cultural, que se torna uma forma de afirmação de grupos sociais variados diante da tendência homogeneizadora que constitui uma das faces do processo de globalização."

\footnotetext{
Países megadiversos, como o Brasil, possuem uma grande riqueza de culturas e etnias e também de recursos da biodiversidade. Essa riqueza constitui a base para 0 desenvolvimento de produtos fortemente ligados a origem e a comunidade local. No entanto, muitas vezes os recursos existentes não são explorados de forma sustentável (econômica, social e ambientalmente) e não geram riqueza e melhoria na qualidade de vida nas comunidades locais. (KRUCKEN, 2009, p.22)
}

Dentro de um cenário rico e diversificado como o território brasileiro, identificar aspectos mais significativos da cultura para transformá-los em produtos e serviços, exige do design uma prática profissional que tem como pressuposto o conhecimento de suas origens e raízes. $O$ design, nesse âmbito, pode ser um recurso estratégico de organização, otimização da produção e 
sustentabilidade, consolidando aspectos identitários peculiares a uma região e promovendo perspectivas de capacitação dos indivíduos que compõem este local. Agregar valor por meio do design a elementos materiais e/ou imateriais, disponíveis em abundância em dado território, configura-se como oportunidade de desenvolvimento para a comunidade local.

Na projetação, deve considerar o indivíduo e tudo que está ao seu redor, desenvolvendo possibilidades envolvendo patrimônio biológico, cultura material e simbólica. Assim, a inovação em design deve garantir uma resposta para as diferentes necessidades das pessoas e, como consequência, melhorar não só as experiências individuais como também a qualidade de vida da sociedade em geral. Krucken (2009) apresenta um conjunto de significados que estão relacionados a área do design, afirmando que a palavra se associa a vários conceitos e interpretações, referindose tanto a desenho como projeto e planejamento. Estes significados foram compilados na Figura 01.

Figura 1 - Ações da projetação em design e possíveis resultados.

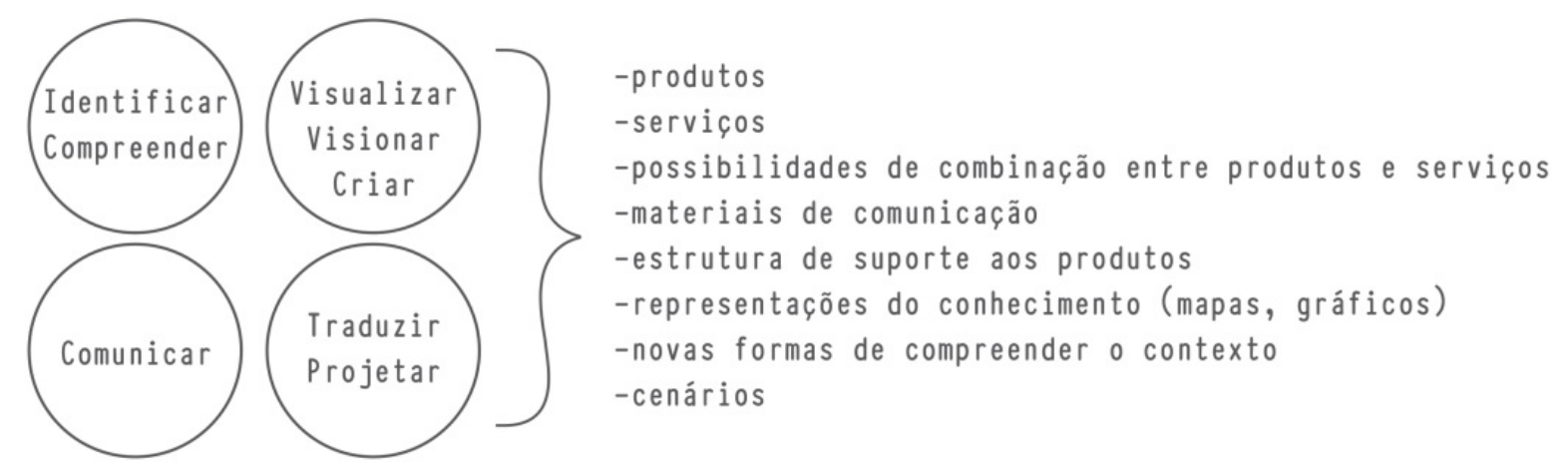

Fonte: KRUCKEN, 2009

Manzini (2008) coloca o design como "um especialista de projeto", que atua em uma rede complexa de atores como um "facilitador de processos". Essa maneira de atuar muda a perspectiva da projetação "para", trazendo à tona o projetar "com". Isso significa que o design pode atuar de forma colaborativa, juntamente aos atores locais, distribuindo a responsabilidade. Para Dalla Vecchia (2009) a interação local e a cooperação são requisitos primordiais para o aprendizado e a inovação, bem como para que as empresas e demais instituições participantes melhorem seu desempenho e reforcem o desenvolvimento local.

Ao contrário da concentração industrial típica dos sistemas de produção de natureza fordistas, cada vez mais, parte da produção e dos serviços vem se concentrando no estabelecimento de novas relações sociais, baseadas em interdependência e cooperação, convergindo para o conceito de redes, que traz implícita a ideia de integração dos fenômenos econômicos, políticos, sociais e culturais. A interação entre agentes visa combinar potencialidades individuais e reduzir as dificuldades. $O$ fato de estarem concentrados no mesmo espaço geográfico facilita as relações e desenvolve laços de confiança e reciprocidade, sendo importante pontuar que isoladamente, talvez não seria possível aspirar a uma participação segura e crescente no mercado de atuação.

Lucca (2012) coloca o processo projetual fundado em dois princípios essenciais: o compartilhamento e a relocalização. O compartilhamento tem a ver com a repartição de responsabilidades, considerando os atores locais como corresponsáveis na resolução de problemas locais e na construção de um futuro em comum. Cada vez mais, observa-se como processos colaborativos podem ter resultados de sucesso, tanto em empresas, como em comunidades. 0 design se coloca neste cenário, de acordo com Lagenbach (2008) como uma ferramenta de empoderamento dos atores locais, pensando projetos juntamente com estes, com base nas 
premissas de sustentabilidade, valorização cultural e diálogo. A partir da cocriação, surge então o codesign, que, para Sanders e Stappers (2008), é a solução resultante da colaboração entre designers e pessoas não treinadas em design, no desenvolvimento de processos projetuais. $\mathrm{A}$ cocriação proporciona a horizontalidade de relações por meio da já mencionada organização em rede, de forma colaborativa e dialogada.

A prática da criatividade coletiva no design existe há muitos anos, e, atualmente, o enfoque dado para a cocriação se modificou um pouco e a proposta é envolver não somente o usuário mas também os atores locais, que tem o entendimento do território, das atividades desenvolvidas, materiais e recursos disponíveis, participando na busca por soluções adequadas. Essa forma de atuação aproxima mais o projetista da compreensão dos valores ali representados, quais as reais necessidades, que tipo de especialistas são necessários para a resolução dos problemas, o que pode tornar o projeto mais eficiente.

\begin{abstract}
"Ao se projetar qualquer objeto, serviços, sistemas ou afins, o resultado desse projeto tem que servir à sociedade que o utiliza. Ou seja, o projeto só tem utilidade e sentido dentro de um determinado contexto, e para entender esse contexto é fundamental que o designer dialogue com os indivíduos que vivenciam esse contexto, entendendo seus imaginários, desejos, mitos, culturas, etc, para entender qual é o impacto do projeto. Por isso, para o desenvolvimento de um projeto em comunidades, que traga melhorias na qualidade de vida, esse projeto precisa ser dialogado e os resultados serão melhores se houver a participação dessa comunidade, trazendo a compreensão de seu sentido. Interessante também é olharmos o designer como um facilitador, desenvolvendo projetos não só com os atores envolvidos, mas também com profissionais de diversas áreas do conhecimento, explorando o caráter multidisciplinar do codesign. (DETIENNE et al, 2004, apud LANGENBACH, 2008, p.42)
\end{abstract}

No entanto, entende-se que, ao desenvolver um projeto para determinada comunidade, é necessário não somente entender seu contexto, as potencialidades dos atores locais, suas limitações, mas também um trabalho de sensibilização para projetar para aquelas pessoas, para que elas se identifiquem com o que está sendo desenvolvido, participem de todo o processo, e se sintam "parte" da solução identificada, garantindo assim maiores chances de que aquele projeto se perpetue localmente quando a equipe que o propôs sair do local ou finalizar sua atuação.

No Brasil, muitas são as propostas de projetos com o objetivo de melhorar a qualidade de vida das pessoas de comunidades diversas, desenvolver novas atividades, dinamizar o território. Por outro lado, é também uma característica intrínseca de várias regiões do país, principalmente as mais afastadas, a descontinuidade das ações que se iniciam. O insucesso de projetos desta natureza é relatado por vários autores, colocando que, após o termino do período de financiamento, eles se tornam insustentáveis. Isso envolve o propósito desta pesquisa, de entender quais ações são necessárias para que a comunidade "caminhe com as próprias pernas" e esse cenário mude. Entende-se que é preciso um "empurrão" inicial para o processo. Porém, não é possível atuar de forma assistencialista, pois isso não dá autonomia para as pessoas que estão trabalhando no projeto. No item a seguir, são apresentados dois projetos com comunidades que ilustram estes problemas, bem como algumas soluções. Ainda são casos isolados, mas que podem ser usados como exemplo do que é possível ser feito, bem como do que pode ser aprimorado.

\title{
2 Iniciativas
}

Para ilustrar as questões identificadas e apresentadas nesta pesquisa, foram selecionados dois casos que tem em comum alguns pontos: o primeiro deles é se realizarem em pequenas comunidades de Minas Gerais, com menos de 10.000 habitantes e que, em sua maioria, atua em áreas rurais e/ou de mineração. Um outro ponto dos projetos selecionados é o fato de que são 
caracterizados como multidisciplinares, com participação ativa de designers no processo, propondo o desenvolvimento de produtos a partir da riqueza local. Estes projetos foram selecionados obedecendo alguns critérios, sendo eles:

- participação ativa ou de observação dos autores deste artigo durante as etapas do processo, tendo acesso às informações do mesmo;

. serem desenvolvidos por ações junto a universidades e/ou negócios locais;

. perfil de valorização da cultura local e capacitação dos atores do território.

Suas peculiaridades serão apresentadas a seguir, bem como alguns pontos de destaque.

\section{Raízes Desenvolvimento Sustentável - Projeto Flores do Carmo}

A Raízes é um negócio social que busca cocriar soluções junto a comunidades de forma a gerar transformações positivas. O projeto apresentado neste trabalho foi nomeado Flores do Carmo e ocorreu em Senhora do Carmo, distrito de Itabira, Minas Gerais, a partir de um programa já executado no local anteriormente. Típica cidade do interior de Minas, tem origem rural e uma população em torno de 3.181 habitantes (IBGE, 2010), sendo que 50\% são mulheres. É um povoado que começou a se formar no ciclo do ouro (séc. XVIII) e a principal fonte de renda era o consumo pelos tropeiros nas regiões de exploração aurífera. De acordo com o Relatório de Diagnóstico feito pela Raízes, o principal ativo econômico é o extrativismo de ouro e minério de ferro e as principais fontes de renda de $80 \%$ da comunidade da zona rural são a agricultura familiar, a pecuária leiteira e a produção de quitandas ${ }^{a}$. No centro, $20 \%$ do povoado presta serviços diversos para moradores e turistas. É lá que se concentra a produção de artesanato e a fábrica de laticínios Carmolac, uma referência local.

Não havia uma técnica tradicional local de produção quando a equipe do Raízes chegou ao local, porém algumas artesãs já haviam trabalhado com tecelagem em 2010, quando a Prefeitura adquiriu teares e contratou uma professora do município de Rezende Costa, em Minas Gerais, para capacitá-las, o que chamou a atenção. Em 2016, algumas das mulheres da comunidade voltaram a se mobilizar junto a associação comunitária para reativar as atividades. O objetivo da proposta feita junto a comunidade pela Raízes foi contribuir para acelerar a consolidação do negócio desse grupo de artesãs e ampliar a geração de renda no local, por meio do desenvolvimento de produtos em tecelagem com as características da identidade local. Identificou-se a necessidade de desenvolvimento de produtos competitivos, com aprimoramento técnico e atenção ao processo de comercialização, otimização produtiva, qualificação e atualização contínua.

O processo então se desenvolveu por meio de uma metodologia fluida, própria da atuação da Raízes, que previa técnicas iniciais de mapeamento e análise do território, para identificar os atores chave do processo, além de oficinas participativas de construção da visão de futuro e formulação de estratégias e plano de ação. Ao longo do projeto, foram realizadas ações de formação e qualificação do grupo para criação dos produtos, além da incubação e aceleração do negócio social coletivo.

Na primeira etapa, de mapeamento, foram realizadas reuniões para levantar informações de forma coletiva, rodas de conversa com moradores tradicionais, além de entrevistas individuais com as artesãs. Houve um levantamento inicial das referências locais, a fim de identificar aspectos peculiares e característicos da região, história, natureza, vida rural, religiosidade, manifestações

a Palavra de origem africana que, em Minas Gerais, significam os produtos como bolos, sequilhos, broas, doces, feitos por produtos vindos dos quintais e servidos com café. A típica mesa mineira que fica posta durante todo o dia. 
tradicionais e o tropeirismo ${ }^{b}$, atividade muito característica da região e que tem grande influencia até os dias de hoje no costume dos moradores locais, inclusive reverberando na alimentação, vestimentas, etc. Foram entrevistados moradores, pessoas que tem grande ligação histórica com a origem e as atividades desenvolvidas antigamente no local.

Figura 2 - Referências imagéticas do tropeirismo e reuniões da etapa de mapeamento.

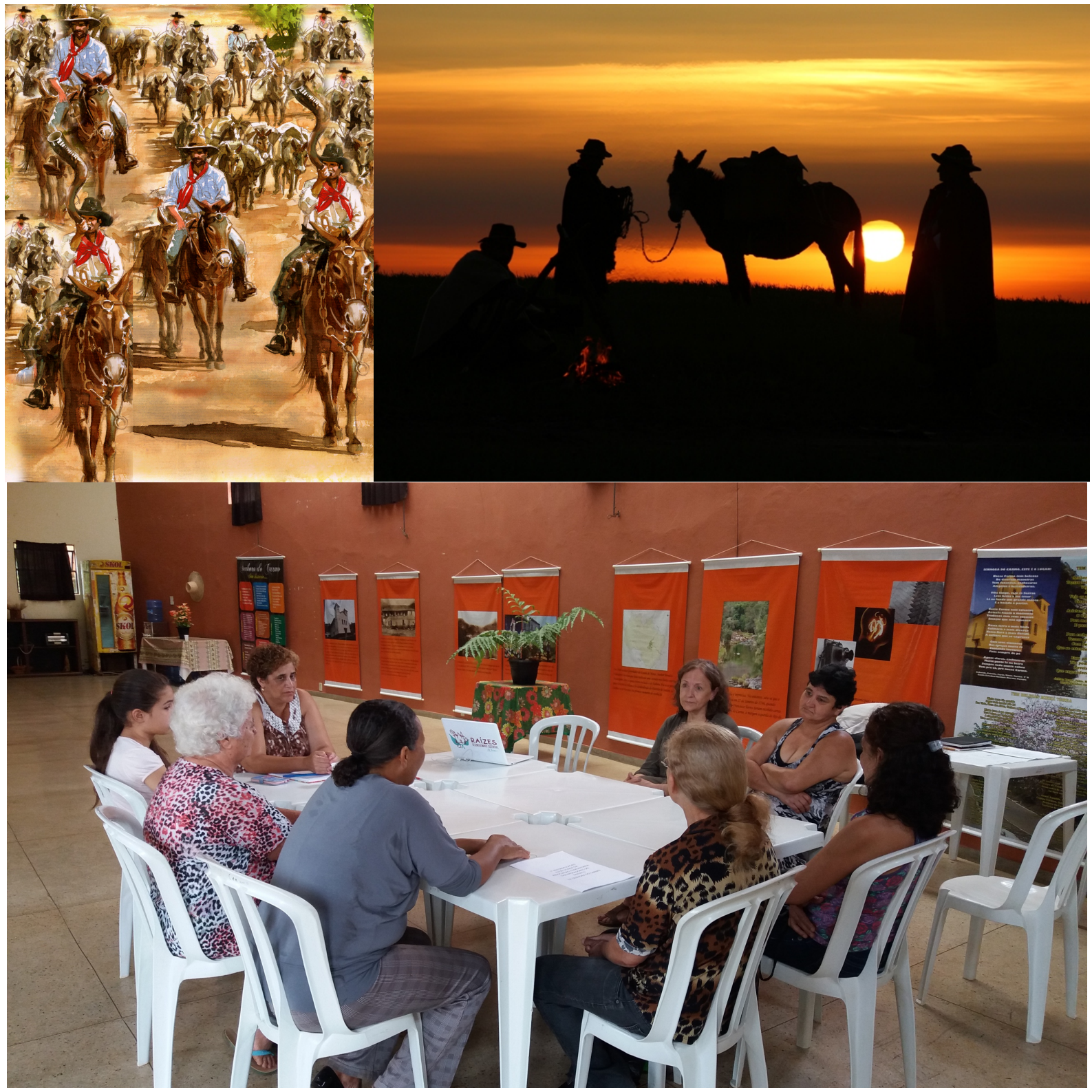

b No Brasil Colonial, os tropeiros tinham uma grande importância econômica, sendo condutores de mulas e também comerciantes. Faziam o comércio de animais entre as regiões sul e sudeste e comercializavam alimentos. Também foram muito importantes na abertura de estradas e fundação de vilas e cidades. 


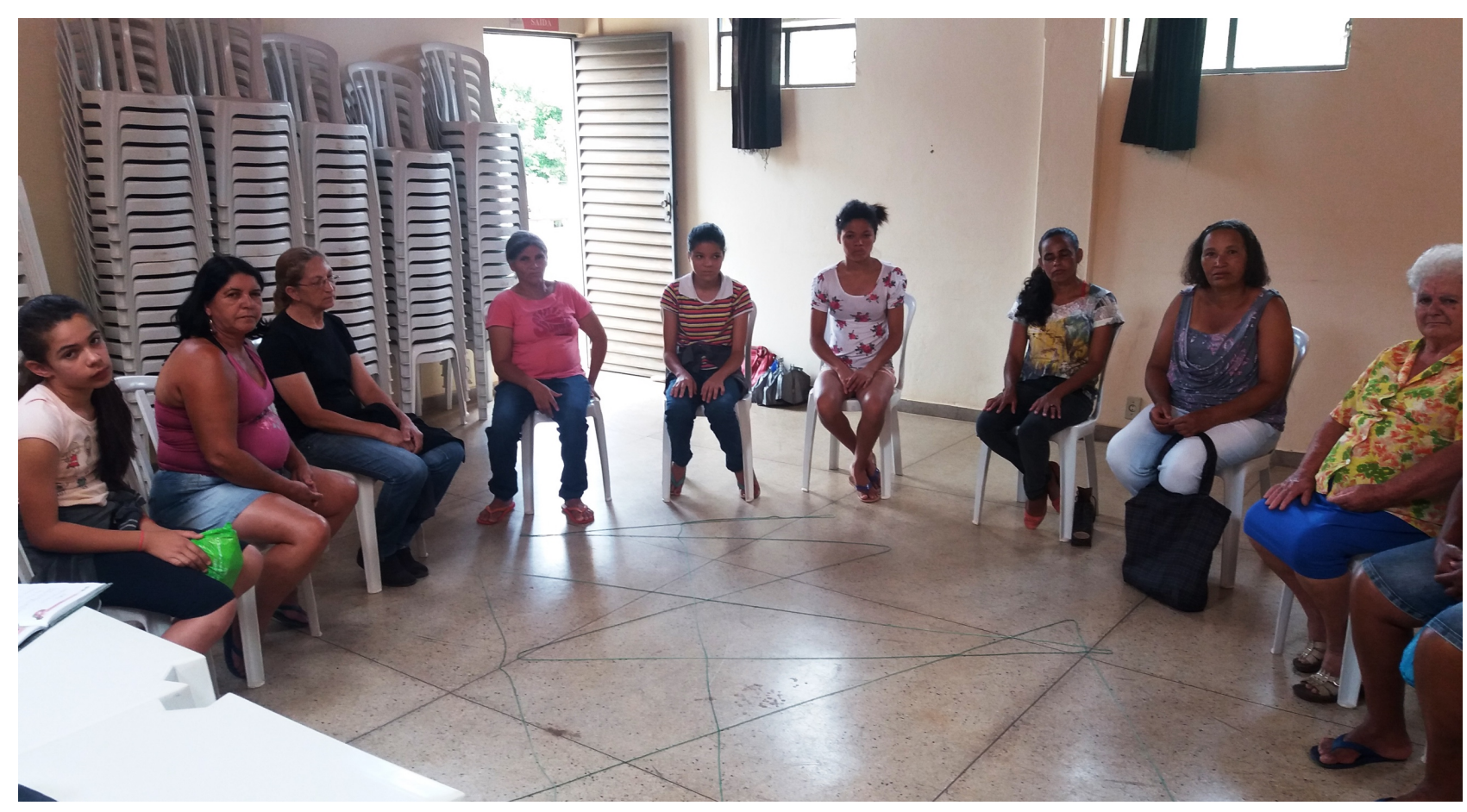

Fonte: https://circuitodoouro.tur.br/blog/2016/10/27/conheca-historia-do-tropeirismo-no-brasil/ Fotografias: Jussara Rocha

Como não havia um negócio implementado para aceleração, mas um grupo produtivo que estava disposto a se organizar para criar uma nova possibilidade de trabalho e renda, foi necessário desenvolver a modelagem do novo negócio, acelerá-lo e consolidá-lo. Para isso, foi proposto pelo Raízes um processo de aprendizado e produção coletiva e, a partir daí, elaborado o direcionamento estratégico do grupo, e depois a construção do plano de ações. As artesãs escolheram o nome Flores do Carmo para o grupo, uma expressão muito utilizada na região para dizer que as mulheres "brotaram" na comunidade de Senhora do Carmo, fazendo referência ao seu nascimento.

A etapa de formação das artesãs envolveu realização de cursos, workshops, palestras e assistência técnica em design, produção, gestão e comercialização. Por esse motivo, ela se mescla a etapa de modelagem de negócio, pois alguns temas foram abordados no módulo de gestão, incentivando as artesãs a refletir sobre a organização e governança de seu negócio social. Foi realizada a definição e o aprimoramento dos produtos e, nas oficinas realizadas, foram cocriados os conceitos de visão de futuro e missão, buscando entender onde o grupo gostaria de chegar de forma coletiva. Todos os temas trabalhados servem como uma forma de sensibilizar a comunidade do seu potencial e do que pode ser feito com ele. Na etapa de mobilização e articulação, fundamentais para no início dos projetos, busca-se encontrar e conectar as pessoas certas.

Figura 3 - Pesquisas de referências das tecelãs do Carmo, atividade de conversa com um antigo tropeiro, reuniões de planejamento. 

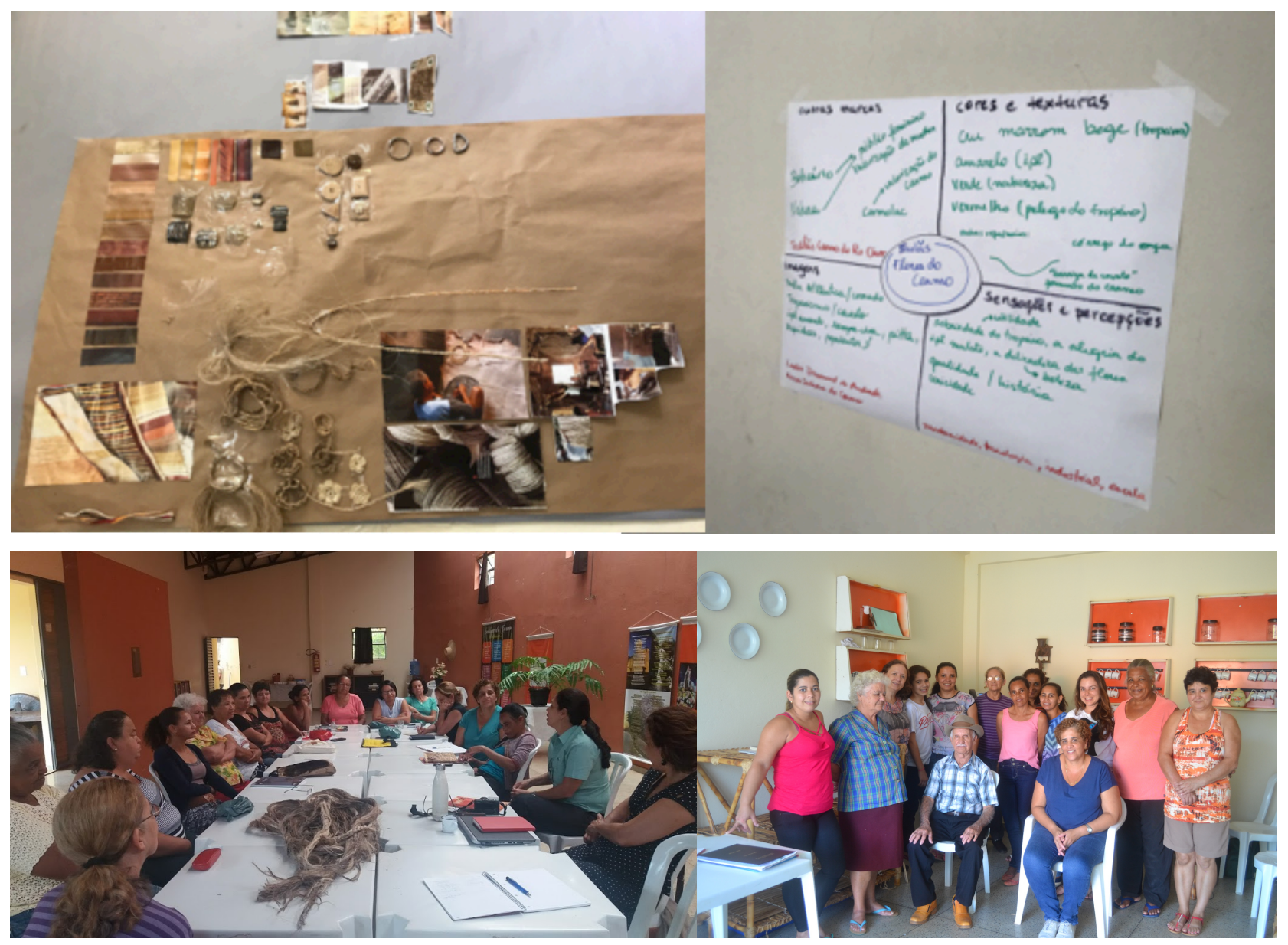

Fotografias: Raquel Canaan e Jussara Rocha.

Outros exercícios foram feitos coletivamente, para compreensão e preenchimento das perspectivas que compõem o mapa, sobre habilidades, competências, objetivos, clientes e recursos e, após a etapa de formação, os produtos passaram a ser desenvolvidos de maneira colaborativa, aproveitando as habilidades de cada uma e de alguns atores locais. Eles eram testados à medida que eram desenvolvidos, avaliando sua eficácia, fazendo alterações e adaptações. Foi possível acompanhar uma pequena parte desta etapa in loco, apresentada nas imagens a seguir.

Figura 4 - Testes com materiais, protótipos de produtos.

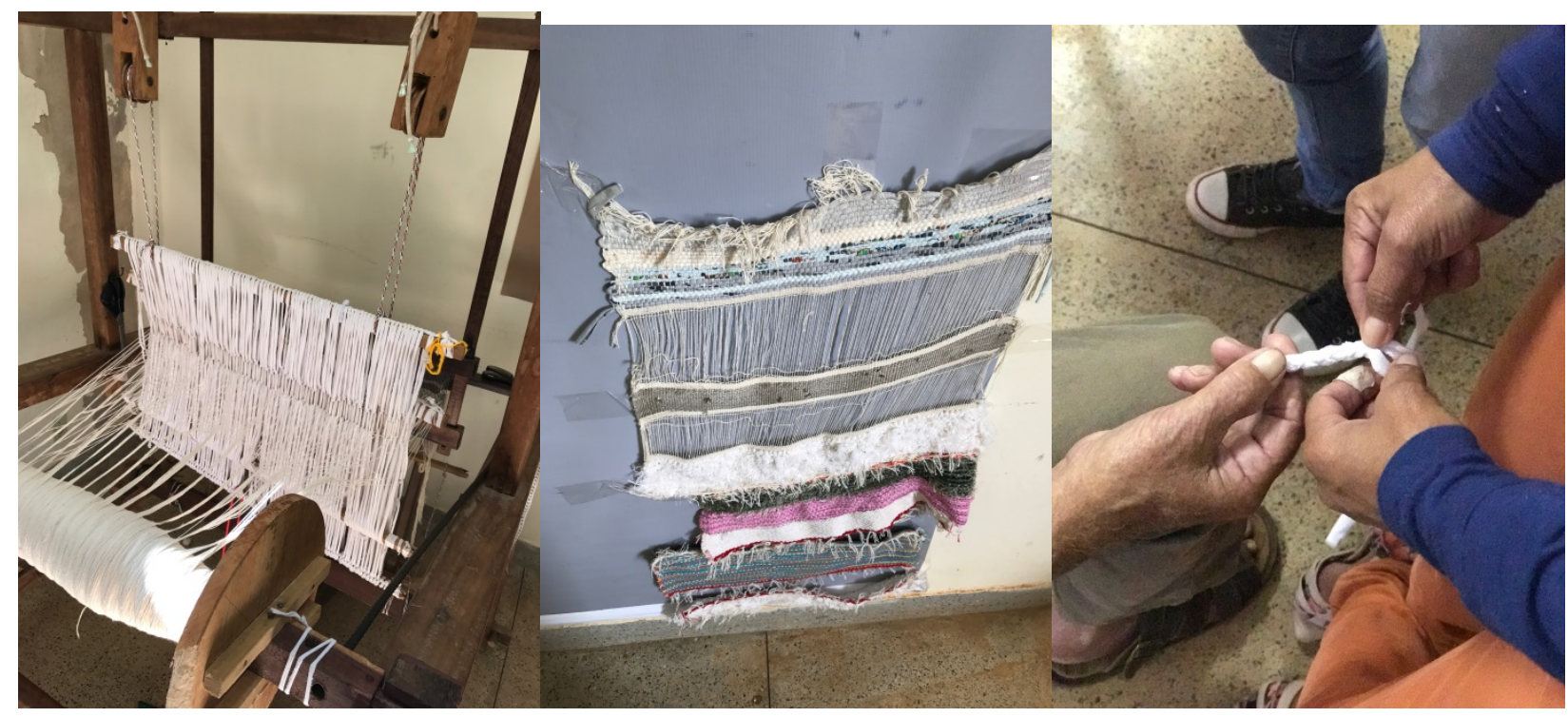




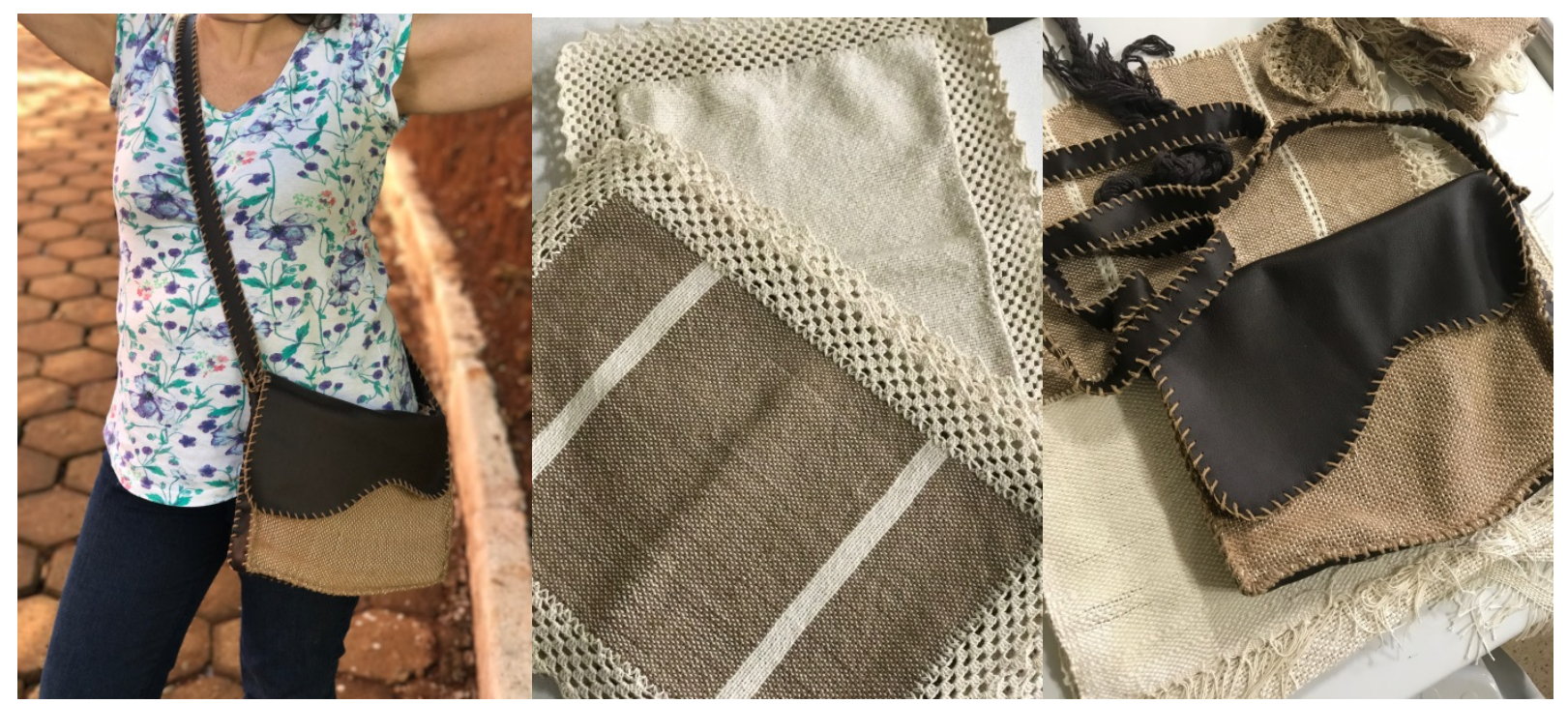

Fotografia: Raquel Canaan.

Atualmente, o projeto está em fase de monitoramento, uma característica da atuação do Raízes, que prevê um acompanhamento periódico, por três anos, ajustando o que for necessário no processo. O foco nesta fase é ampliar a produção e incrementar a comercialização, participando de feiras e eventos de artesanato, o que vem acontecendo desde o ano passado. $O$ grupo também se cadastrou no Programa Nacional do Artesanato e são agora consideradas artesãs profissionais, podendo submeter-se a editais de feiras e comercialização, como o Salão Nacional de Brasília, que aconteceu em maio de 2019 , onde fizeram a inscrição e participaram por sua conta, sendo muito bem avaliadas e se articulando com outros parceiros. Atualmente, estão desenvolvendo novos produtos de acessórios femininos e dedicando-se a comercialização e comunicação, por meio do seu sitec, além da busca por uma sede própria. Também estabeleceram parcerias com comunidades vizinhas, como as Bordadeiras de Ipoema, produzindo produtos em colaboração.

Figura 5 - Equipe, Produtos do projeto e produtos desenvolvidos em parceria com as bordadeiras de Ipoema

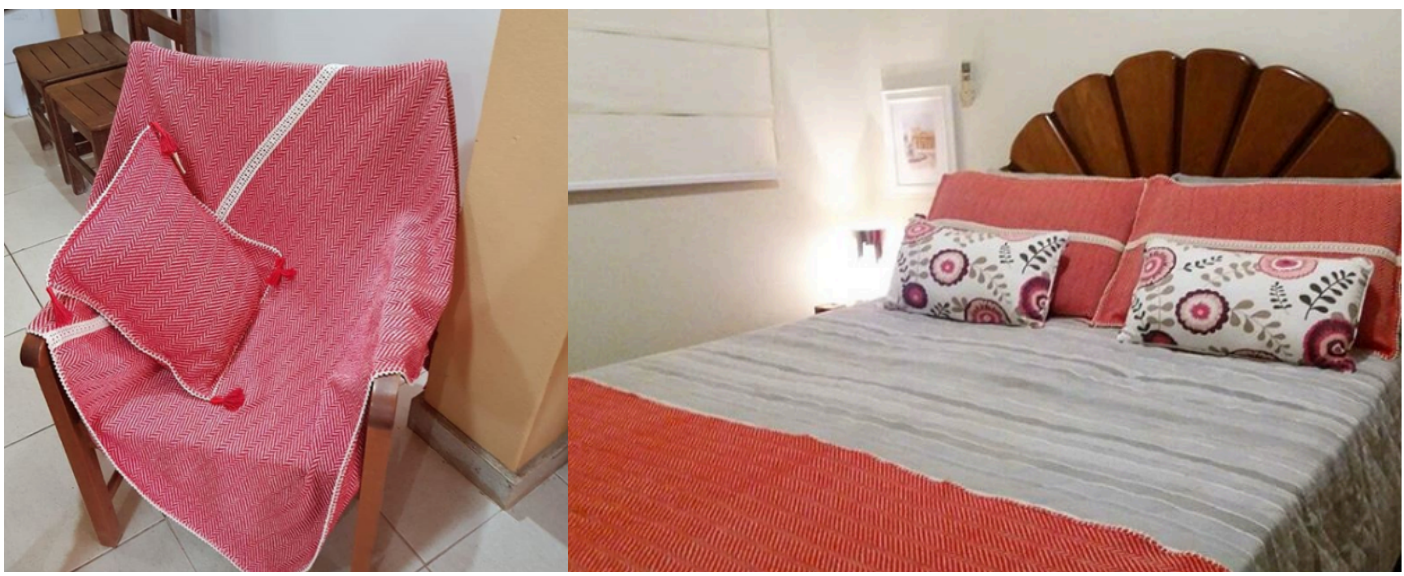

c Disponível em : www.floresdocarmo.com.br 


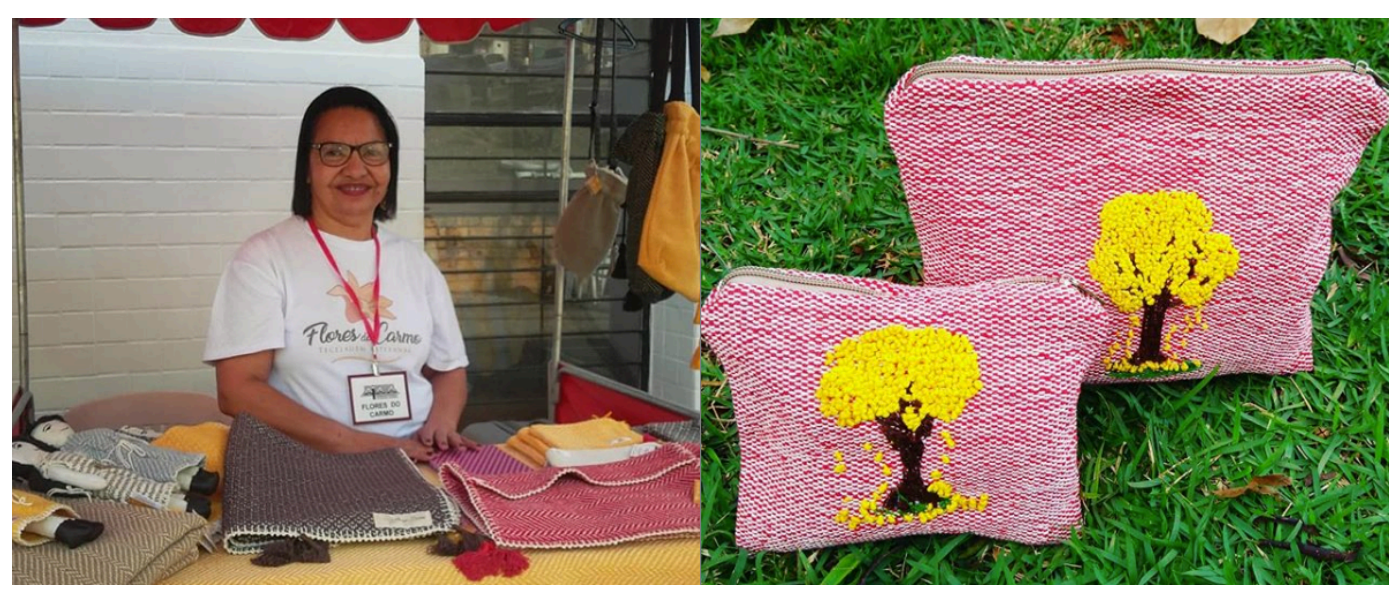

Fonte: Instagram.

\section{ITAPORARTE}

O território do Vale do Jequitinhonha, localizado no Nordeste de Minas Gerais, é formado por 80 municípios distribuídos em uma área que representa aproximadamente $14,5 \%$ do Estado. A Macrorregião Jequitinhonha/Mucuri está situada em uma das maiores províncias gemológicas do mundo, mas, em contraponto, é a região mais pobre do Estado de Minas Gerais, carente de recursos diversos. Em razão disso, é alvo de várias ações governamentais em todos os níveis. No entanto, a região possui uma vasta cultura popular, com características como o cancioneiro, o artesanato local (principalmente a cerâmica e a tecelagem), além dos "causos", benzedeiras e curandeiros, das festas religiosas e brincadeiras que compõem o rico patrimônio imaterial do Jequitinhonha.

A cidade de Coronel Murta está situada no território do Vale, com uma população em torno de 10.000 habitantes e a economia amparada na extração mineral. A principal fonte de renda da população está relacionada às atividades informais de mineração, predominando o garimpo. Por estar inserida na Província Pegmatítica Oriental do Brasil, apresenta uma grande riqueza mineral.

O projeto ITAPORARTE nasceu de uma possibilidade identificada no âmbito de um outro projeto realizado em parceria entre Universidades de Minas Gerais. Seu objetivo era a melhoria de aspectos da qualidade e sustentabilidade nos níveis da cadeia produtiva do setor de gemas e joias. Além disso, apresentava-se como uma resposta a uma demanda da comunidade de Coronel Murta por capacitação no setor voltada para a população mais jovem da região.

A região de Coronel Murta não faz jus riqueza de sua terra, por não ter por costume produzir produtos derivados desta riqueza, sendo que as pedras extraídas na região são exportadas sem nenhum beneficiamento. Porém, a equipe identificou abundância de feldspato, considerado rejeito da extração mineral, disponível como material passível de aproveitamento pela agregação de valor pelo design. Assim, dois principais aspectos identificados pelo PROGEMAS foram considerados na proposta: a possibilidade de beneficiamento de gemas de menor valor e outros materiais descartados na extração mineral e o ambiente propício ao seu desenvolvimento, por contar com o apoio e a participação de alguns agentes locais, com destaque para a Prefeitura Municipal e o Sindicato dos Garimpeiros de Coronel Murta e Baixo Jequitinhonha.

Como o município de Coronel Murta não possui tradição no desenvolvimento de artefatos minerais, a proposta do projeto foi utilizar as reconhecidas características culturais do Vale do Jequitinhonha aliadas ao potencial humano da região, fator primordial para as ações desenvolvidas no território. Para atender ao proposto no Projeto Itaporarte, foram então necessárias ações para inserir as pessoas da região, além de capacitações alinhadas com a proposta do mesmo. Na etapa de desenvolvimento de produto, foram realizadas oficinas que trabalharam os aspectos comunicacionais, materiais e tecnológicos (figura a seguir), buscando identificar soluções. 
Figura 6 - Aspectos trabalhados nas oficinas orientadas de desenvolvimento de produto.

\begin{tabular}{c|c|c|}
\hline COMUNICACIONAIS & MATERIAIS & TÉCNICO/TECNOLÓGICO \\
\hline \begin{tabular}{c|c} 
e conteúdos simbólicos a serem \\
aplicados nos produtos.
\end{tabular} & $\begin{array}{c}\text { utilização da matéria prima } \\
\text { disponível na região como insumos } \\
\text { e rejeitos dos pegmatitos. }\end{array}$ & $\begin{array}{c}\text { técnicas tradicionais associadas } \\
\text { à inovação tecnológica. }\end{array}$ \\
\hline
\end{tabular}

Fonte: Teixeira (2007).

Durante o projeto, as visitas e encontros entre os pesquisadores e os moradores da região contribuíram para a integração de ambos e a coleta de informações, que serviram de subsídio para a concepção dos modelos mais factíveis e alinhados aos aspectos locais. Na imagem a seguir, estão apresentados os materiais utilizados no desenvolvimento das peças que eram, além do feldspato, cascalhos de turmalina e os pigmentos naturais encontrados na região.

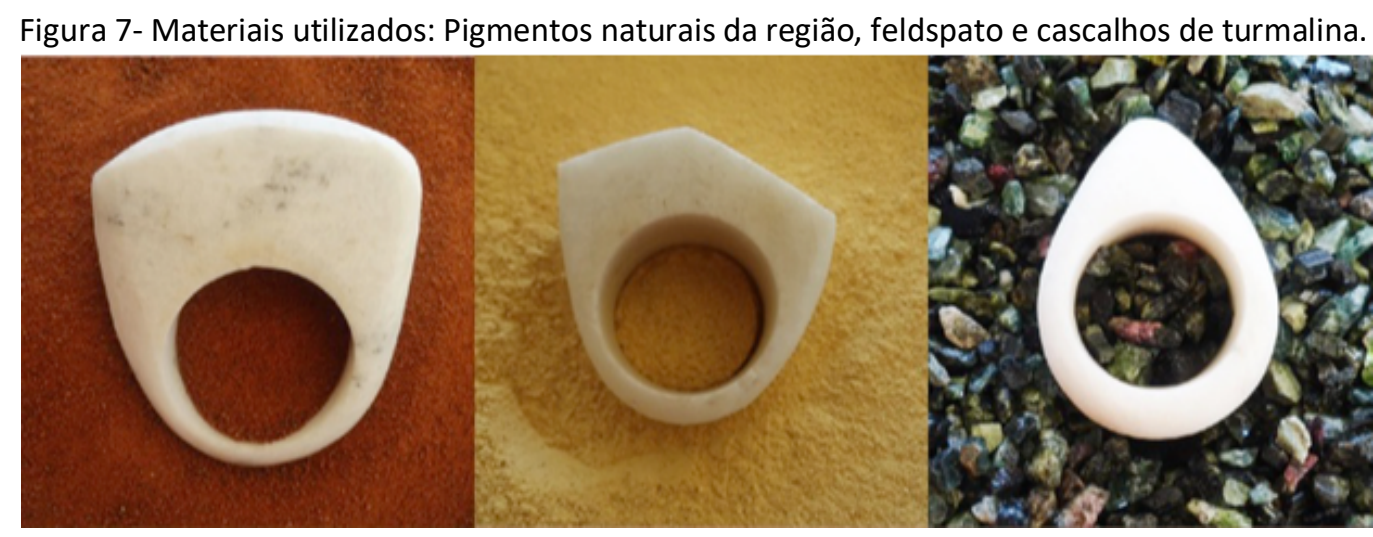

Fotografia: Raquel Canaan.

A partir da proposta apresentada, cujo projeto foi premiado, os produtos evoluíram para uma produção com técnicas de baixa complexidade, para permitir o rápido aprendizado da lapidação nos equipamentos do Laboratório instalado e tornar possível posteriores contribuições formais dos próprios produtores, ampliando e reforçando os aspectos iconográficos e identitários da região.

O Laboratório Itaporarte teve por finalidade a produção de artesanato mineral, atuando na transferência de conhecimento e capacitação de pessoas da comunidade para produção. Inicialmente a capacitação foi proposta em três especialidades: lapidação, inclusão de turmalinas e pintura de superfície, habilidades necessárias ao desenvolvimento dos produtos propostos para serem produzidos nesta unidade. Instalado o laboratório, era necessário ter pessoas da região atuando ali e operando as máquinas e equipamentos, que foram treinadas para repassar esta capacitação in loco.

Os procedimentos de capacitação para produção foram organizados em etapas produtivas desde a seleção da matéria prima, passando pelo corte, conformação e acabamento final, permitindo ao aprendiz a prática de todas as etapas produtivas. A metodologia de ensino foi fundamentada na prática dos procedimentos de produção, incluindo a teoria necessária ao conhecimento das técnicas e materiais usados na produção.

Figura 8 - Equipe em capacitação no Laboratório Itaporarte. Coronel Murta, Vale do Jequitinhonha. 

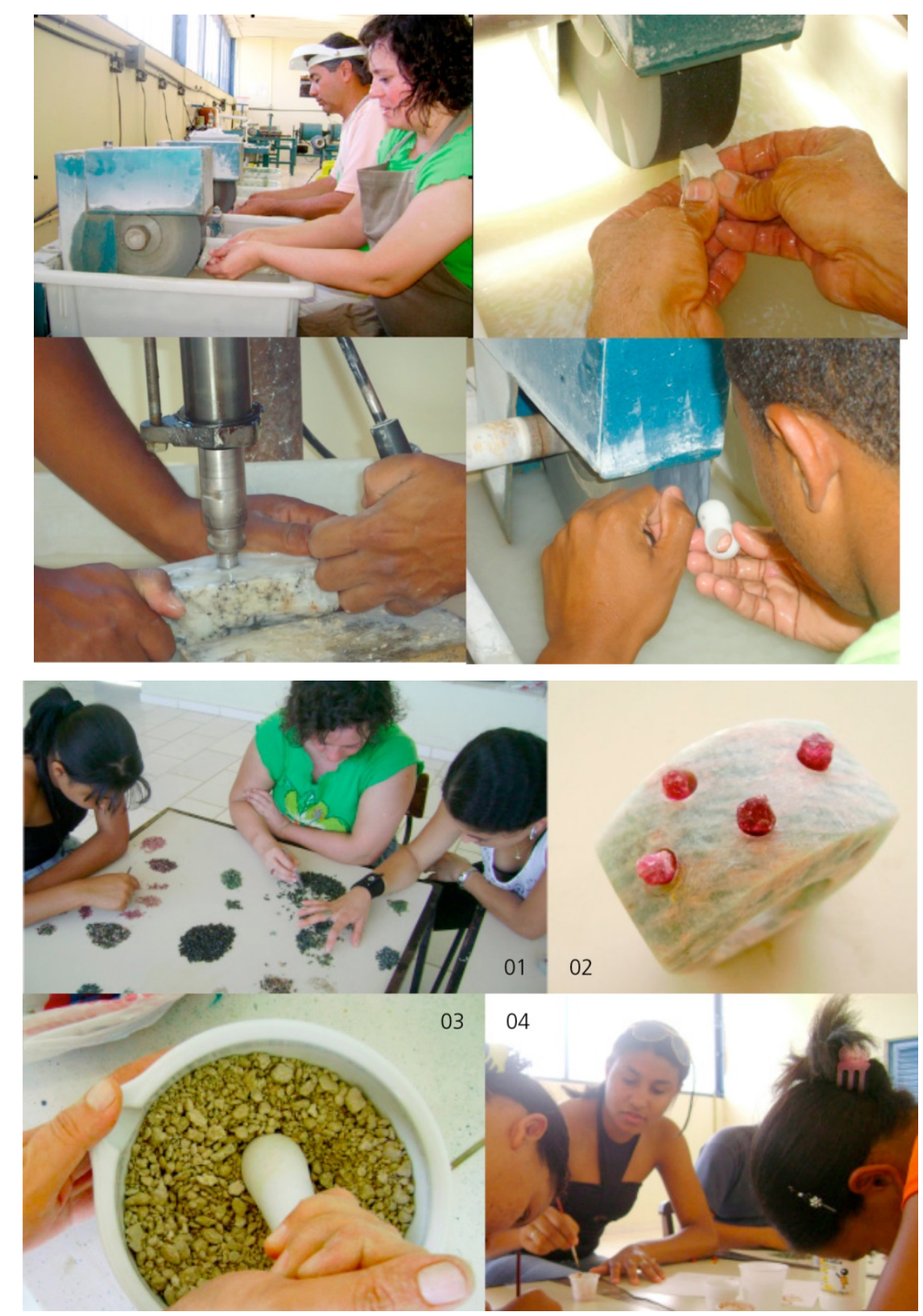

Fonte: Teixeira (2007)

A capacitação e o treinamento são processos contínuos, que deveriam se desenvolver de forma permanente na região pelos técnicos extensionistas treinados no Centro de Estudos em Design de Gemas e Joias, em paralelo ao desenvolvimento e testes com os produtos. A primeira turma capacitada envolveu trinta e cinco jovens em níveis diferentes de capacitação, incluindo habilidades básicas, médias e mais avançadas.

No momento em que os produtos começaram a ser produzidos em escala, outros jovens locais se interessaram pelo Projeto e passaram a trabalhar voluntariamente no Laboratório, em busca de uma oportunidade de capacitação e especialização. Nessa etapa, foi possível perceber a cidade "abraçando" o Projeto, pois tanto a comunidade local como seus apoiadores reconheceram os produtos como típicos da Região, traduzindo a identidade e a riqueza material local e representando-a em feiras em todo o país.

Como desdobramento desse envolvimento, foi assinado em 2012 um Termo de Compromisso da Prefeitura de Coronel Murta com a Universidade do Estado de Minas Gerais e o Sindicato dos Garimpeiros de Coronel Murta, constando o comprometimento da comunidade, 
durante dez anos, em apoiar as Ações do Laboratório Itaporarte, a cessão do espaço onde funcionava e o contrato de três extensionistas da região para atuar no laboratório.

Figura 9 - Produtos da linha Itaporarte na paisagem da região com o Rio Jequitinhonha.

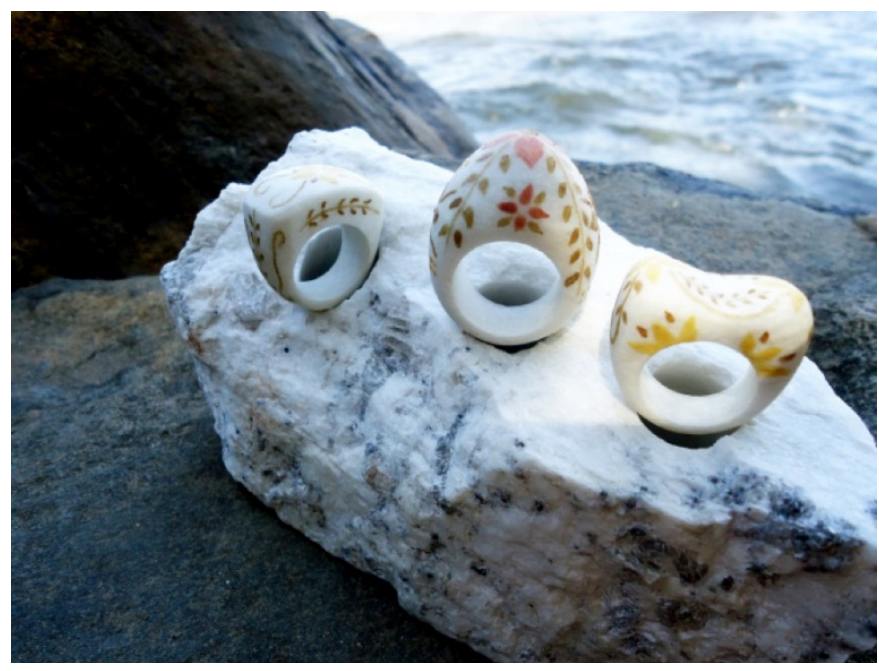

Fotografia: Raquel Canaan

A proposta de artesanato mineral do laboratório Itaporarte em Coronel Murta apresenta design com forte apelo identitário e estético, respeitando em seu processo produtivo relações de sustentabilidade em diversos aspectos. Até hoje foram capacitados e treinados no laboratório trinta e cinco pessoas que podem vir a produzir uma média de duzentas peças por mês, como a linha de anéis que faz parte da primeira coleção e outras já projetadas que incluem linhas de joias, souvenirs e objetos decorativos. Os projetos trabalham a transferência de conhecimento e tecnologia geradas no CEDGEM ${ }^{d}$, envolvendo alunos bolsistas e professores na capacitação tecnológica de pessoas da comunidade na produção de artefatos em artesanato mineral, compondo o vértice de iniciativas de sustentabilidade social do projeto.

Assim, o projeto configura-se como uma inovação social, onde foram criadas novas oportunidades a partir de um problema do setor, com apoio de agentes locais e o respaldo da equipe da UEMG, capacitando e empregando mão de obra disponível. O projeto agrega valor não só à cultura local como aos recursos humanos disponíveis na região. Além disso, a ideia do uso do output de um sistema como recurso para delinear outro sistema foi aplicada, de forma a aproveitar também o material disponível localmente.

\section{Considerações}

Alguns pontos importantes percebidos no acompanhamento destes projetos são destacados aqui, alinhados com a proposta deste estudo. O primeiro passo para o desenho de um projeto em um território ou organização é conhecer suas características e especificidades. Para Jussara Rocha, uma das sócias do Raízes, isso confere legitimidade ao processo, porque se constrói junto e se conhece melhor por meio do mapeamento.

Ao longo de seu desenvolvimento, vários tipos de pesquisa são realizados, como dados secundários, entrevistas, visitas de campo e outras fontes que permitam uma maior aproximação e compreensão do lugar e das pessoas que ali habitam. A necessidade de se entender o DNA social local, pelas palavras de Jussara, é latente, bem como o vínculo que já existe, além de despertar a confiança de quem ali está. Este é o primeiro passo para a definição do objetivo do projeto, e da

\footnotetext{
${ }^{d}$ Centro de Estudos em Design de Gemas e Joias da Universidade do Estado de Minas Gerais.
} 
forma como ele será construído, pois envolve o entendimento do território.

Na visão do projeto, trabalhar a governança é sempre necessário porque são as pessoas que guiam o local. Para Jussara, a governança é fundamental, e deve ser construída e mapeada. Nem sempre é uma governança "oficial". Ela utiliza as palavras proximidade e sensibilidade, na busca por reabrir a janela do sentimento do morador pelo lugar, quando ele passa a perceber melhor o local onde vive, bem como o seu papel naquela realidade.

O planejamento participativo coloca em circulação a inteligência coletiva, empodera os atores e gera sinergia. Para isso, a cocriação sempre deve permear as etapas, ou seja, a construção é feita junto com os atores locais, por meio de reuniões criativas, desenho coletivo de soluções e organização de eventos, fóruns de consulta e participação, com o intuito de articular e otimizar a inteligência coletiva e potencializar ao máximo a cooperação.

Por fim, existe uma etapa no processo da Raízes que, neste estudo, é considerada primordial, e que em muitos casos conhecidos, não ocorre, muitas vezes por falta de verbas ou porque o tempo do projeto acaba. Muitos projetos em comunidades não dão certo por falta de um acompanhamento adequado. Mais que dar autonomia, é necessário apoiar por um tempo as ações, por meio de um monitoramento periódico, tentando garantir que elas tenham êxito. Isso envolve mensurar impactos, apoiar o grupo, manter uma comunicação após a finalização do projeto por determinado período. Entende-se aqui como uma maneira de apoiar e dar segurança para que aquele grupo "se firme", desenvolva sua autonomia e siga em frente com a proposta.

Por outro lado, a capacitação dos atores locais feita de forma não assistencialista, dando a eles autonomia, preparando-os também para gerir o negocio, sempre aberta a adaptações de acordo com as necessidades identificadas é um ponto importante identificado, bem como o respeito ao tempo, necessidade e processo de cada grupo, construindo com eles de forma sustentável para que possam caminhar com as próprias pernas quando o projeto acabar.

A partir dos resultados obtidos com o Projeto Itaporarte, é possível concluir que pequenas ações educacionais e tecnológicas podem, no caso específico de Coronel Murta, mas também de outros municípios, contribuir para uma real e positiva transformação social, econômica e ambiental e, que essas pequenas ações podem desencadear um processo gradativo de desenvolvimento local, a ser reproduzido em outras comunidades.

Apesar de alguns problemas encontrados no confronto com a realidade local, como os relacionados a conciliação de distância, tempo e infraestrutura, que atrasaram e dificultaram o desenvolvimento do projeto, um ponto importante a ser ressaltado como perspectiva de continuidade e desdobramento dos projetos é a adesão da comunidade. O entendimento local da importância do design na construção e diferenciação do produto, não só como estética, mas como agregação de valor, foi um fator determinante para a aceitação do projeto, pois foram criados laços de confiança com a população, que entendeu a importância de sua participação nas ações do projeto destinado a eles. Esta adesão se configura como um ponto muito significativo para resolver o problema dos projetos sem continuidade, pois são um fator de sustentabilidade para as ações desenvolvidas.

Ainda há muito o que caminhar no sentido de dar autonomia e "projetar com" comunidades, mas as experiências vivenciadas e estudadas levantam pontos em potencial que podem ser trabalhados, aprimorados e adaptados a realidades diversas. Essa troca é essencial no sentido de aprender, colaborar e criar junto, sempre com a atenção voltada ao benefício dos atores locais.

\section{Referências}

DALLA VECCHIA, R. V. R. Arranjos Produtivos Locais como Estratégia de Desenvolvimento Regional 
Local. Paraná: UECO, 2009.

DIAS, R. Turismo e Patrimônio Cultural - recursos que acompanham o crescimento das cidades. São Paulo, Saraiva, 2006.

KRUCKEN, L. Design e território: valorização de identidades e produtos locais. São Paulo: Studio Nobel, 2009.

LANGENBACH, M. L. Além do apenas funcional. Inovação social e design de serviços na realidade brasileira. COPPE,UFRJ, Rio de Janeiro, 2008.

LUCCA, A. S. Design Participativo para a Valorização da Produção do Território. In: 10o CONGRESSO BRASILEIRO DE PESQUISA E DESENVOLVIMENTO EM DESIGN - P\&D DESIGN, 2012, São Luís. Anais. São Luís: UFMA, 2012.

MANZINI, E. Design para a inovação social e sustentabilidade: comunidades criativas, organziações colaborativas e novas redes projetuais. Rio se Janeiro: E-papers, 2008.

SANDERS, E. B. N., STAPPERS, P. J. Co-creation and the new landscapes of design. CoDesign, 4(1), 5-18, 2008.

TEIXEIRA, M.B.S. Projeto de implantação de laboratórios para ampliação de pesquisa na área de desenvolvimento de produtos do centro de estudos em design de gemas e jóias da escola de design. Projeto Especial de Pesquisa FAPEMIG. Universidade do Estado de Minas Gerais, 2006.

WHITE, O. M. Inovação e Criatividade em Pesquisa. In: PERDIGÃO, Dulce Mantella; HERLINGER, Maximiliano; WHITE, Oriana Monarca. Teoria e prática da pesquisa aplicada. Rio de Janeiro, Elsevier, 2011. 